\title{
Exploration Of Themes And Design Concepts As A Communication Form In Architecture
}

\author{
Tita Cardiah \\ Interior Design, Faculty of Creative \\ Industry,Telkom University, \\ Bandung Indonesia \\ titacardiah@telkomuniversity.ac.id
}

\author{
Irwan Sudarisman \\ Interior Design, Faculty of Creative \\ Industry,Telkom University, \\ Bandung Indonesia \\ irwansudarisman@telkomuniversity.ac.id
}

\begin{abstract}
Interaction between architectural objects with observers (public) as one form of communication in architecture, especially communication in the language of architectural forms. Communication in the architecture will be established if the realization of architectural forms has clear themes and concepts. Exploration of design themes and concepts in architecture as part of the design process both normative theory and positive theory to produce architectural forms that are capable of creating design characteristics, meaning and philosophy. Exploration The design themes and concepts, especially public buildings, can be through a glass box or black box design process, this is influenced by the client, function, location and even local government policies and regulations. The object in this discussion is the result of the design of the Architecture Final Project and the subject of Architectural Design 6 in the Architecture Engineering Department of the Indonesian Science and Technology College STINTEN Bandung. This research is a research with qualitative descriptive method, which is compiled based on the data of several architectural final project. This study is intended to examine that communication in architecture is the language of architectural forms that result from exploration of themes and design concepts.
\end{abstract}

Keywords: Exploration, Theme and Concept of Design, Communication, Architectural Form.

\section{INTRODUCTION}

Objects and architectural forms visually not only present the aesthetic beauty of the design physically, but save a lot of stories, messages, meanings, philosophies to mythology for certain communities. This condition shows that the world of architecture has a very diverse and free form of communication. It is said to be diverse and free meaning language in architectural communication through architectural objects such as verbal language, non-verbal, composition of forms, visuals, and symbols. The establishment of architectural objects that are able to create communication between the subject and the object of architecture is the existence of processes and stages of architectural planning and design, these stages are exploration of themes and design concepts. The success of "architectural objects" is through the exploration process of themes and design concepts.

Exploration The design themes and concepts in the architectural process of embodiment are very important stages as a whole in the planning and design process to produce communicative architectural design. Themes and concepts become a unity because the theme is the basis for determining a concept, meaning that a concept without a theme is an untitled design, so that architectural work does not become the object of communication between subject and object.

\section{METHODE}

This research uses descriptive qualitative method, which is research that seeks to describe how exploration of themes and design concepts as a form of communication in architecture. Data collection used qualitative methods, namely various literature data related to the discussion of research and sample data of design work with the object of Final Project and subject of Architectural Design 6 from students of the Architecture Engineering Study Program ST-INTEN Bandung.

\section{CONCEPT AND DESIGN PROCESS}

The architect, the architectural student and the design teacher are all involved with the making of building forms. there are many valid techniques, models, paradigms, idioms and processes for designing, learning design and teaching design, all with the same essential goal of providing successful architecture in every sense. They all serve as vehicles or catalysts for improving our effectiveness as designers, to broaden and deepen our understanding of design activity and to organize and present information about designing. One of these, the nation of "concepts" will be used here to present some thoughts about architectural design (Edward, T White, 1975, p. 10).

One way of understanding more about design is to chart a route through the process from beginning to end. The communication of one or more solutions to people inside or outside the design team (Bryan Lawson, 1980, p.12). This approach is a method of exploration of design themes and concepts as processes and stages in planning and design to produce architectural works that can communicate various ideas, ideas, philosophies, mythology to cosmology between subject and architectural objects.

Traditionally, architectural concepts have been the designer's way of responding to the design situation presented in the program. They have been the means for translating the non-physical problem statement into the physical building product. Every project has within it what might be described as prime organizers, central themes, critical issues or problem essences" (Edward, $T$ White, 1975, p. 10). "Concepts in architecture are 
normally though of as belonging to the schematic design phase of the planning process. This traditionally has been where the designer has generated the "big ideas" for the building design. The concepts in these planning phases may be directed at the evolving building design or may address the procedures to be followed within the process phases (Edward, T White, 1975, p. 12).

In the interdisciplinary domain of architecture, conceptual terms are used to describe the elements of a design and its envisioned experience. Terminology is used to conceptualize the site, organization of space, use functions, form, scale, and styles or precedents, among other design elements (Schön, 1983) (Rolf Steier og Palmyre Pierroux, 2011). The relationship between 'seeing and doing' architectural practice has also been investigated by Schön (1983), who describes the architectural process as one of 'reflection-in-action', where the designer makes or tries a design decision through drawing or modelling, follows through with that decision's consequences, and then responds to those consequences with new action.

In architecture and artistic expressions, for example, volume and form are seen as an integral part of a design's structural logic, which is 'controlled by the primary concept of something to be expressed' (Arnheim, R. , 1969).

\section{RESULTS AND DISCUSSION}

Exploration of themes and design concepts in an architectural object can be done through two design methodologies, namely black box method and glass box method. Architectural design with black box method is a planning and design process that is carried out completely by the architect / designer without interference or involvement of other parties including clients. The exploration of design themes and concepts with black box method is purely the product of the architect / designer's own ideas, covering the rationale and process of ideas, ideas, problem seeking, problem solving, synthesis, themes, concepts until the realization of architectural form.

Architectural design with glass box method is a planning and design process that involves various parties such as clients. The exploration of themes and design concepts with this glass box method prioritizes openness and transparency in determining and deciding various matters relating to design is the result of mutual agreement.

\section{Hotel and Commercial Center}

The Hotel and Commercial Center is the result of the Final Project of Architecture Engineering Students on behalf of Eka Cahyana Nugraha, NIM 02211008. The location of the project is on the road of the Bandung People's Security Agency (BKR).

\section{The Concept of Compounding Building Mass}

a. Application of the Podium Mass in response to the Neighborhood
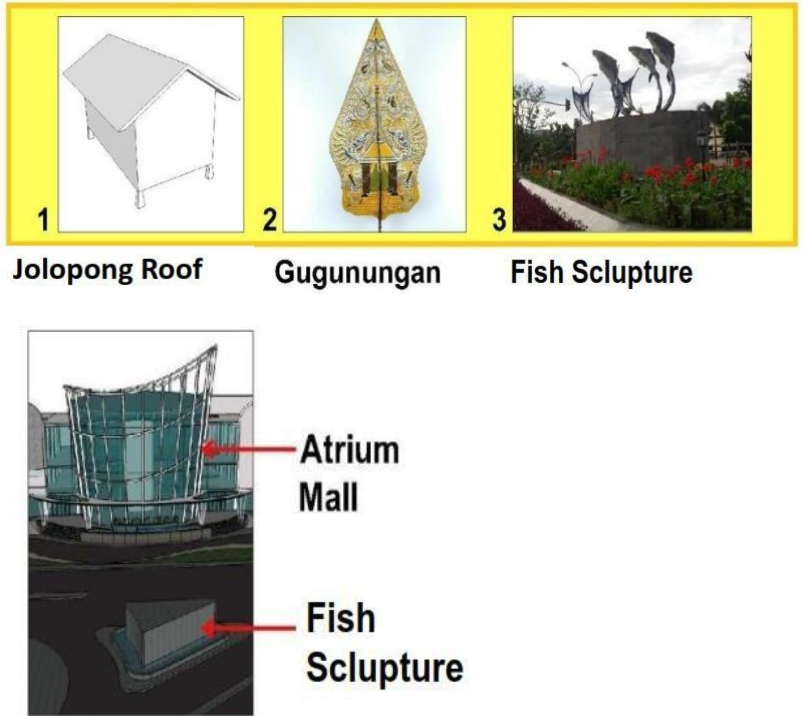

Figure 1. Hotel Podium Source: Nugraha, Cahyana, Eka

Podium building mass is a response to a fish statue that represents the scale of the surrounding environment, a fish statue in a straight line with the Atrium mall forming an axis line, the attitude towards a fish statue is treated with an atrial facade that resembles a fishnet, as if there is a connection between the Fish \& Podium Statue.

b. Application of Tower Mass to Local Cultural Elements

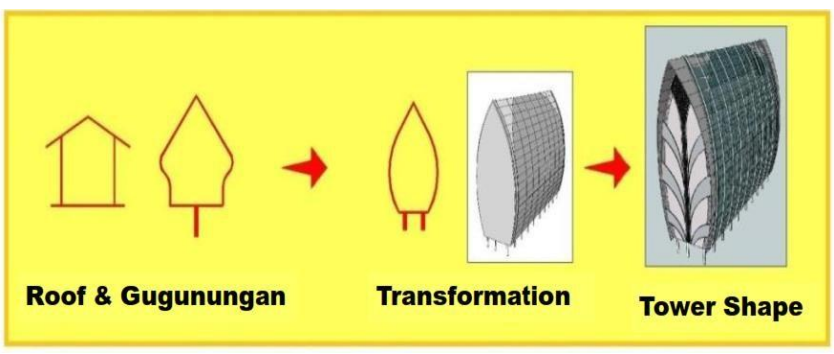

Figure 2. Hotel Tower Source: Nugraha, Cahyana, Eka

The shape of the hotel tower is a mass response of the building to the city scale with characteristics that reflect Sundanese culture.

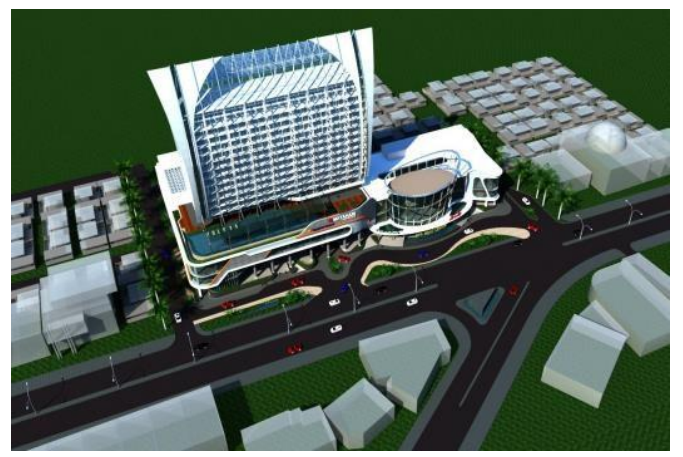




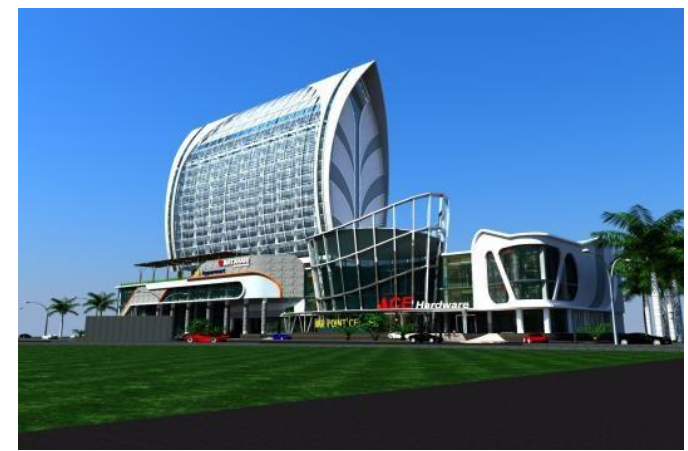

Figure 3. Hotel and Commercial Center Source: Nugraha, Cahyana, Eka

The shape of the tower which tends to bend using the air circulation that enters the hotel room area is more focused (cross ventilation). In the hotel room, using the empty space as a balcony, this is so that the structure in the curved plane is not too far / long. Fluency in the language of form is important to the articulation of a creative idea in the physical building just as these qualities are relevant to the expression of a creative idea verbally or in written form (Edward, T White, 1975, p. 28).

\section{A. City Hotel Pasteur Bandung}

City Pasteur Hotel is the result of the Final Project of Architecture Engineering Students on behalf of Deny Herjanto, NIM 02206801. Project location at Pasteur Bandung street with a land area of $31,205 \mathrm{~m}^{2}$.

Concept of Building shape
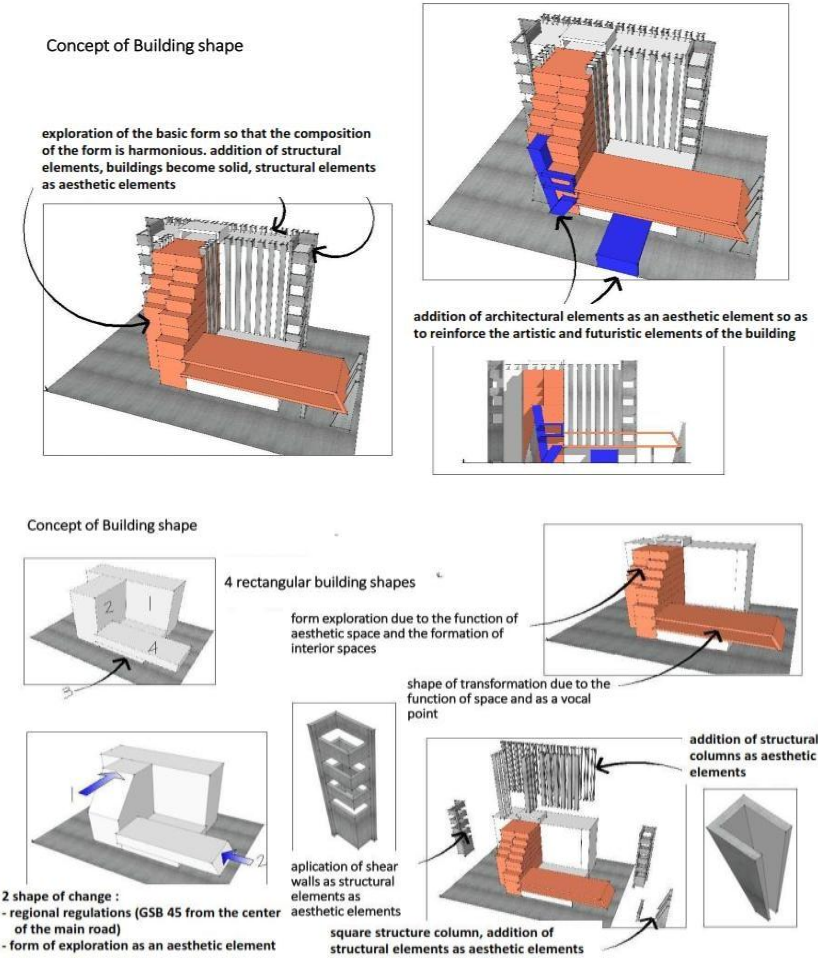

Figure 4. The Concept of Building Mass Source: Herjanto, Deny a. Atmosphere

- Calm and calm embodiment of the pilotis concept.

- Clean and modern (the cleanliness of the facilities and the scope of facilities that are modern).

- Safe and intimate are things that must be considered and emphasized from the structure to protect the sense of security of the user and to realize Bandung as a city of convention that is quite well known among consumers both nationally and internationally.

The basic concept of creating a city hotel with consideration of structure and construction as the focus and priority of the dominant problem and wanting to lift the mass of high buildings so that circulation and open space become concrete free.
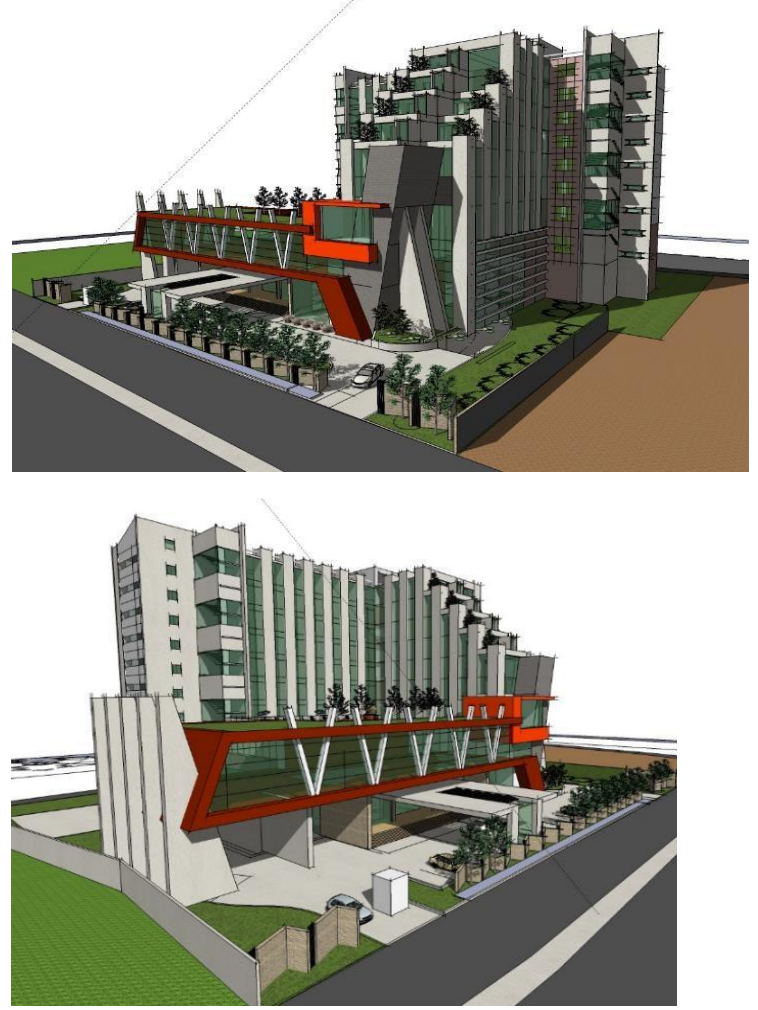

Figure 5. Composition of Building Mass Source: Herjanto, Denny

A piece of information may be critical and needed early in one design project since it has a strategic impact on the solution, but the same kind of information in another project may not. This will depend on all the other constraints which are at work in each case. Thus the idea that briefing is an early stage in the design process that consists of a one-way flow of information from client to designer, although persistent, is extremely misleading. For these reasons briefing is probably best managed by designers, either those working on the project or at least other having a real practicing experience of designing. This could also account for the widely reported problems of using project manager in this role of design (Bryan Lawson, 2004, p. 29). 


\section{B. Braga Gallery Arts Center}

Braga Gallery Arts Center is the result of Architectural Design VI of Architecture Engineering Students on behalf of Adhy Andriaman, NIM 02213014. The project location on Braga street No. 16 Bandung (Dekranas Jabar Cultural Heritage Building) with a land area of $31,205 \mathrm{~m}^{2}$.

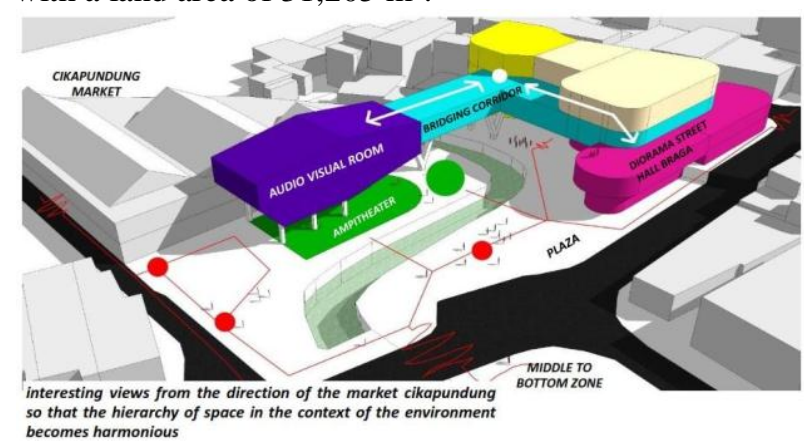

Figure 6. Composition of Building Mass Source: Adriaman, Adhy

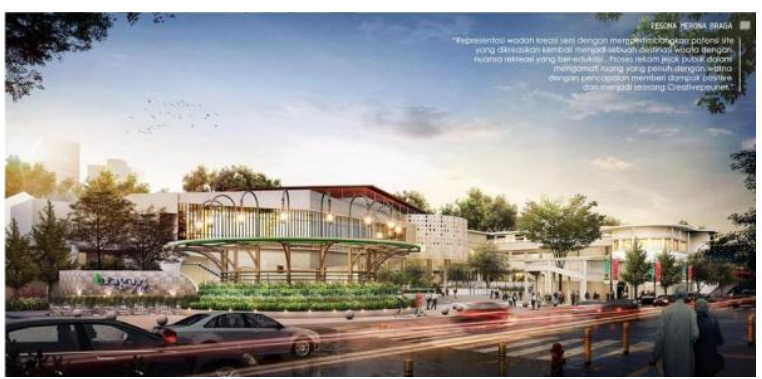

Figure 7. Composition of Building Mass Source: Adriaman, Adhy
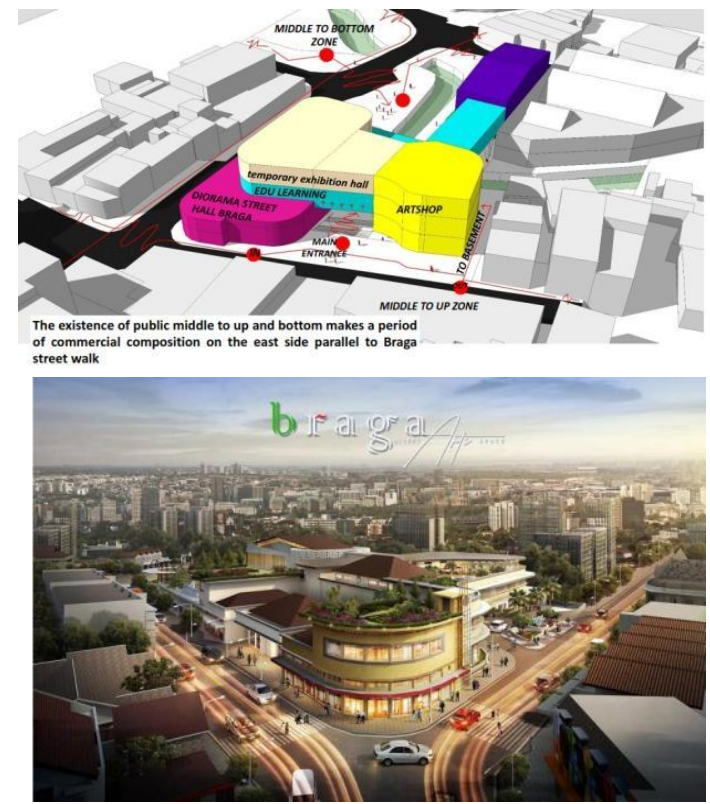

Figure 8. Composition of Building Mass Source: Adriaman, Adhy

The project did needs and requirements faced by the designer are real and the number of architectural solutions that will be successful for a given problem are limited (Edward, T White, 1975, p. 28).

\section{CONCLUSION}

Communication between subject and architectural objects is influenced by various backgrounds of subjects as observers or respondents, such as age, gender, culture, and profession. While architectural objects are influenced by location, function, shape and aesthetics.

The theme in architectural design is a representation of the overall abstract design as a common thread of the architectural planning and design process which will eventually become the spirit or soul of the architectural work. The concept in architectural design is the implementation of a theme that has been determined from the beginning of the planning and design process. The concept as a synthesis of problem solving in a design can be implemented in various forms of mass, composition of space, color, material, aesthetics and enrichment.

Professional practice is merging previously separate design protocols. Sustainable Design, Building Information Modeling, and Integrated Practice are combining formal design with continuous performed evaluation... and the profession is looking to the schools to be part of the transition (Leonard Bachman, Christine Bachman, 2009).

\section{REFERENCES}

1. Bryan Lawson, 1980, How Designers Think, The Architectural Press LTD. London.

2. (Schön, 1983) (Rolf Steier og Palmyre Pierroux, 2011).

3. (Arnheim, R. , 1969).

4. Open Design Methodologies. Exploring architectural practice for systems design Hilda Tellioglu \& Ina Wagner Rüdiger Lainer Multidisciplinary Design and CSCW Master School of Architecture Technische Universität Wien Academy of Fine Arts in Vienna Argentinierstr. 8, A1040 Wien, Austria Office: Reisnerstr. 41, A-1030 Wien, Austria +43 158801 (Ext. 4492, 4439) + 431713 37

htelliog,iwagner@pop.tuwien.ac.atRuediger_Lainer@blac kbox.at

5. OLSON VALERIE."TRANSHABITATION: UNIVERSALIZING ARCHITECTURE." Into the Extreme: U.S. Environmental Systems and Politics beyond Earth, University of Minnesota Press, Minneapolis; London, 2018, pp. 143-180. JSTOR, www.jstor.org/stable/10.5749/j.ctvgd2z0.

6. Brady, R., 2017. Why Millenials Need Less Studio Time in Architecture https://architizer.com/blog/architectureeducation/.

7. Bachman, L. \& Bacman, C., 2009. Affecting Change in Architectural Education. ARCC Journal, 6(1.)

8. Ikatan Arsitektur Indonesia, 2007. Kode Etik Arsitek dan Kaidah Tata Laku Profesi Arsitek. Jakarta: Badan Sistem Informasi Arsitektur Ikatan Arsitek Indonesia.

9. Schön, D. A. (1983). The Reflective Practioner: Basic Books.

10. Arnheim, R. (1969). Visual Thinking. Berkeley: University of California Press.

11. Bryan Lawson, 2004, What Designers Know, The Architectural Press LTD.Oxford.

12. Edward, T White, 1975, Concept Sourcebook, a Vovabulary of architectural forms, architectural media LTD, Arizona. 